\title{
MALDIVIAN RESORT SONEVA FUSHI - THE SYNTHESIS OF SUCCESSFUL BUSINESS AND ENVIRONMENTAL SAFETY
}

\begin{abstract}
Vasilevich N.I., PhD, LabProMedia Ltd., nvasile2003@yahoo.com
Today, the question of the influence of human activity on the state of the Earth's biogeosystem has become especially acute. In 2015, the UN adopted the concept of sustainable development, i.e. development that meets the needs of the present without compromising the ability of future generations to meet their own needs. Environmental problems were among the main topics of the 50th World Economic Forum, held in Davos in January 2020. During the discussion of these issues, a significant confrontation was revealed with the authorities and business on one side and civil society on the other.

Is it realistic to combine business success with environmental concerns? In 1995, the five-star Soneva Fushi resort was opened on the uninhabited island of Kunfunado in the Maldives, where profitability and the principles of sustainable development were integrated. "We believe that the goals of the company's activities must not only be the income of shareholders, but a common contribution to the development of the company", the company's website says. The founders of the company Eva and Sonu Shivdasani call this approach responsible tourism. The company uses the most resource- and energy-saving technologies, almost completely processes produced waste, and since 2012, thanks to the sponsorship of charitable environmental projects, has a net zero carbon balance. The article describes the principles and technologies that enable the company to combine economic benefits and environmental safety.
\end{abstract}

The Maldives is a group of islands in the Indian Ocean, which are home to a little more than 380 thousand people. Of the nearly 1,200 coral islands, almost not rising above sea level, only 200 are inhabited. With a total area of thMaldives being $90000 \mathrm{~km}^{2}$, the land area occupies only $298 \mathrm{~km}^{2}$, and the largest island, Male, covers an area of $6.8 \mathrm{~km}^{2}$. The mild climate, warm sea, clean beaches attract many tourists, and 70 islands have been turned into tourist resorts. However, the hospitality business is facing certain difficulties in the Maldives.

There are no rivers in the Maldives, and only a few islands have lakes. The only sources of water for local residents are wells and reservoirs that are filled during rains. Therefore, water must be either imported in plastic bottles or desalinated directly on the island. The beaches of the Maldives are covered with thin white sand, composed of dead particles of corals, washed ashore and grounded by sea waves. Its composition mainly includes limestone, and not the quartz fragments characteristic of building sand. The fertile soil layer of the coral islands is very thin and not rich, it originates from dying parts of plants and accumulates only in the jungle; in open spaces the soil is actively washed away by the rain and carried away by the wind. But many crops grow on imported soils in warm and humid climates: bananas, mangoes, papaya, cucumbers, zucchini, greens and much more.

The main source of energy in the Maldives is imported diesel fuel, and only a small part of the electricity is produced using solar panels.

One of the most painful problems of the Maldives is waste disposal. Almost everything but coconuts are brought into most of the islands; and all combustible waste, mainly consisting of packaging and plastic containers, is burned in an open fire on the leeward side of the island. The artificial trash island, located $7 \mathrm{~km}$ from the capital of the Maldives, and named Thilafushi, is notorious. The decision to create it was made on December 5, 1991, and on January 7, 1992 it received the first cargo of garbage. As a result, an island stretched out 3 kilometers appeared on the site of a shallow lagoon, about 800 meters wide, with a large harbor inside. Environmentalists say that over 330 tons of garbage arrived at Thilafushi every day for 20 years, and only in 2011 the government banned the transportation of garbage to the island. Nowadays, the bulk of the garbage mostly goes to India.

In 1995, Eva and Sonu Shivdasani opened a luxury hotel on the uninhabited island of Kunfunadoo. The 
Table 1. Comparative characteristics of the most popular desalination technologies [2]

\begin{tabular}{|c|c|c|c|}
\hline Technology & Proportion, \% & $\begin{array}{l}\text { Heat consumption, } \\
\qquad \mathrm{kW} \text { heat } / \mathrm{m}^{3}\end{array}$ & $\begin{array}{l}\text { Electricity consumption, } \\
\qquad \mathrm{kWh} / \mathrm{m}^{3}\end{array}$ \\
\hline Multi-Stage Flash Distillation & 43,5 & $80-120$ & 2,5 \\
\hline Reverse osmosis & 43,5 & NA & $1-3$ \\
\hline Multi-Column Distillation & $\sim 10$ & $50-90$ & $3-6$ \\
\hline
\end{tabular}

name of the resort was the encryption of their own names: Soneva Fushi. As their motto, they took the words of Henry Ford: "The company should be a tool for serving people, and not just a machine for making money". Soneva Fushi was the first resort to combine the luxury and principles of sustainable development adopted at the UN World Conference in Rio de Janeiro in 1992. Sustainable development refers to a strategy that meets current needs, but does not compromise the ability of future generations to meet their own needs. Following these principles, the company uses the most resource-saving and energy-saving technologies, the most consumer products are produced on-site, allowing to reduce transportation and carbon dioxide emissions, and, in addition, almost all waste produced on the island is completely processed. The company's carbon footprint in 2018 amounted to 60,377 tons of $\mathrm{CO} 2$, of which $82 \%$ was attributable to indirect emissions, which mainly included air travel to resort guests [1]. Thanks to participation in a number of charitable environmental projects since 2012, the company as a whole has a zero carbon balance.

Let us take a closer look at the technologies that have allowed a luxurious five-star resort to become a practically closed-loop company that does not have a negative impact on the environment.

\section{DESALINATION OF WATER}

Desalination is the process of removing mineral salts from seawater, resulting in production of water suitable for human use or for irrigation. It is believed that water with a salt content of not more than 500 ppm is suitable for drinking. There are different ways of industrial desalination, the most popular among them being multi-stage flash distillation (Multi-Stage Flash Distillation), multicolumn distillation and reverse osmosis (Table 1) [2].

In multi-stage flash distillation, sea water is heated to $120^{\circ} \mathrm{C}$ at enhanced pressure, so that boiling does not occur; then it is introduced through a special nozzle into a large chamber. The decrease in pressure entails the instantaneous conversion of part of the water into steam. This process occurs at each stage, and as a result, desalinated water has a salt content of less than 50 ppm, and the cost of $1 \mathrm{~m}^{3}$ of water does not exceed 1 dollar.

During multi-column distillation, sea water is heated by steam in the columns, while part of the water evaporates; the resulting steam goes to heat in subsequent columns, which leads to the evaporation of the next portion of water. Each stage uses the energy of the previous stage, with successively lowering temperatures and pressures, so the energy consumption with this desalination is minimal. The cost of $1 \mathrm{~m}^{3}$ of water is 0.7 dollars.

The reverse osmosis process involves the use of a semipermeable membrane that transmits water and traps impurity molecules. This is the most energy-consuming process. The cost of producing $1 \mathrm{~m}^{3}$ of water is $\$ 0.5$, and the salt concentration is usually about 500 ppm. The membrane distillation technology, that uses a h. membrane which transmits steam but not droplets of water, is very close to the reverse osmosis technology.

Membrane distillation as a way of desalination involves the passage of the hot salt solution through a hydrophobic membrane made of PTFE, PVDF or PP with an average pore size of $0.2 \mu \mathrm{m}$, which is permeable to water vapor, but not to liquid water, thereby ensuring almost complete removal of non-volatile impurities. The driving force of membrane distillation is the partial pressure difference of water vapor between the two boundary surfaces, which occurs as a result of the differences of temperatures of these surfaces. As a rule, the temperature difference between 5 and $20^{\circ} \mathrm{C}$ provides the difference necessary for the process. Depending on the design of the condensing / permeable system on the other side of the membrane, membrane distillation is divided into different types: direct contact membrane distillation (DCMD), air gap membrane distillation (AGMD), permeate gap membrane distillation (PGMD), etc. The over- 

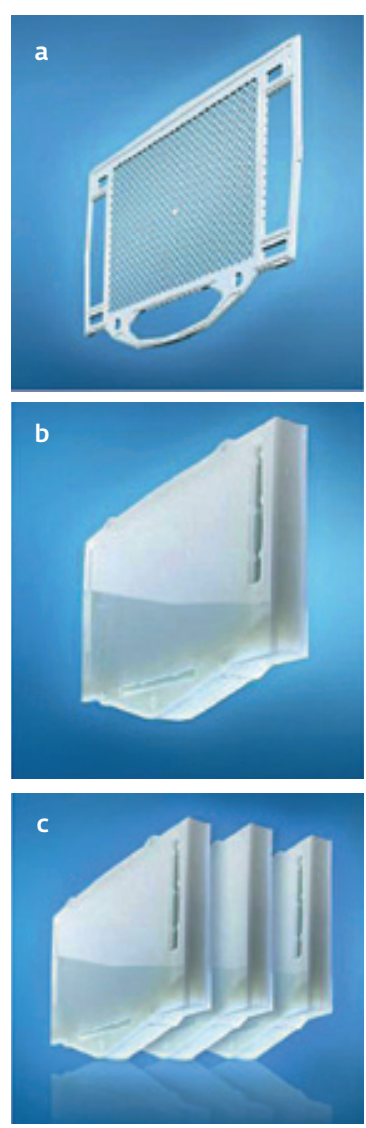

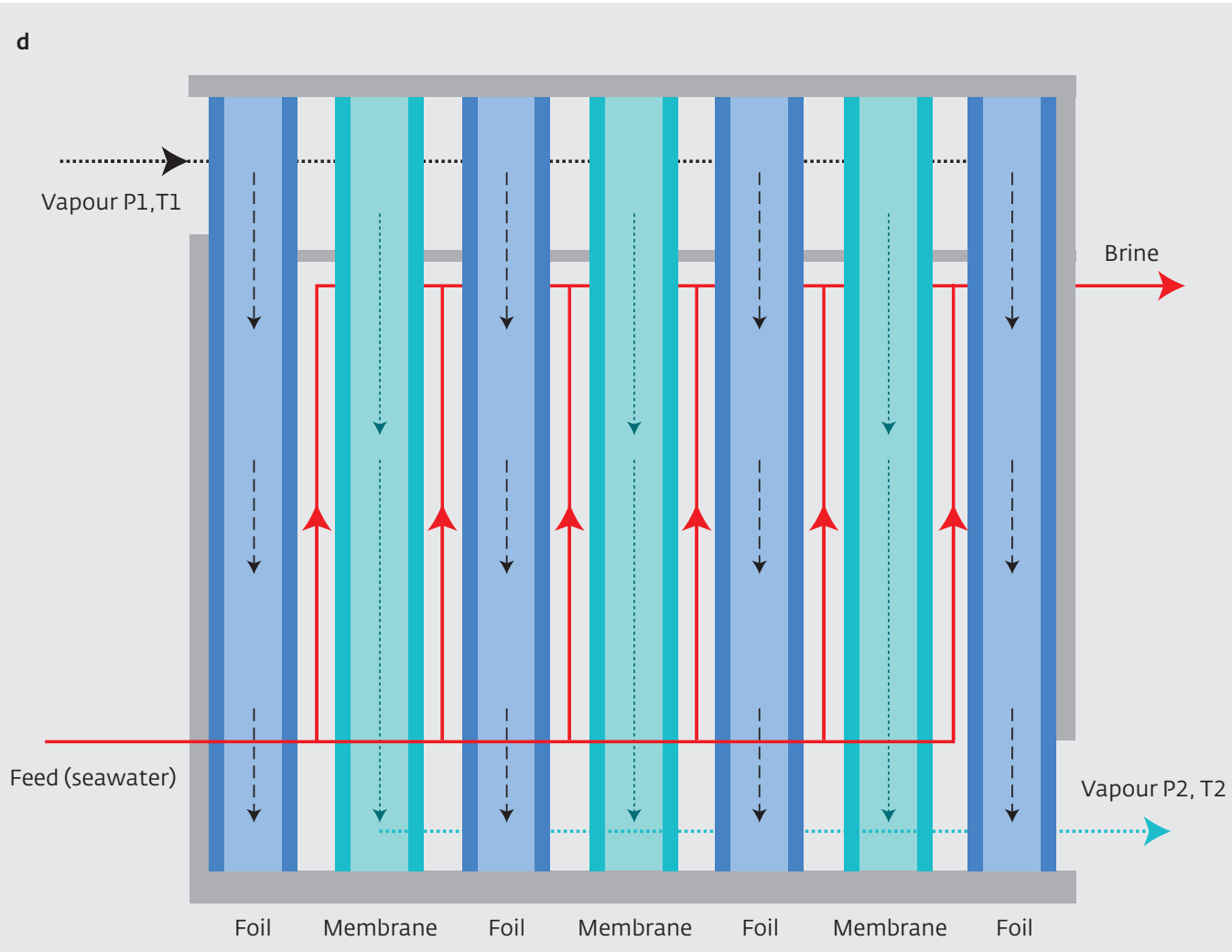

Fig.1. A frame with a double polypropylene membrane or film (a), an evaporation-condensation stage (b), a sealed design consisting of multiple stages (c), a flow diagram of the feed solution, saline and steam in a single stage (d)

view of commercially available membranes potentially suitable for desalination of sea water is presented in [3]. Today, one of the most promising technologies is the vacuum method of multi-stage membrane distillation, or V-MEMD, patented by Memsys Water Technologies $\mathrm{GmbH}[4]$. This technology is used to desalinate water at Soneva [5].

The desalination system consists of a steam generator, evaporation-condensation modules, and a condenser; and the use of the vacuum from the permeate side accelerates the distillation process. Each evaporation-condensation module consists of alternating frameworks with a double polypropylene or polytetrafluoroethylene membrane and frameworks with a polypropylene film; channels are formed between the frameworks: frameworks with a film create distillation channels, frameworks with a membrane - channels for steam, and a feed channel is formed between the membrane, and film frameworks solution. The modules are fastened together and sealed with silicone gaskets. Steam enters the module, passes through the membrane and condenses on the frame with the film, and then condensed water enters the distillation channel. The heat of condensation is transferred through the film and converted into evaporation energy, generating new vapors in the seawater supply channel, which is limited by the condensing film and the membrane. Steam penetrates through the membrane and collects in the steam channel, then passes through the second membrane and condenses on the next condensing film. The schematic diagram of each module is shown in Fig.1. The thermodynamic rationale for the technology of vacuum multi-stage membrane distillation is given in $[6]$.

The process takes place at moderately low temperatures $\left(<90^{\circ} \mathrm{C}\right)$ and moderate negative pressure, all components of the module are made of polypropylene, which eliminates corrosion and hardness scaling, and also allows for large-scale, cost-effective production. Today they produce industrial plants with a capacity of up to 24 tons / day [7], where the degree of desalination exceeds $99.95 \%$ [4].

Researchers at Memsys comprehensively studied the possibility of a desalination plant operating on solar 
panels and the factors affecting the efficiency of the process [7]. The desalination of water at Soneva Fushi is fully supplied by the energy produced by the photovoltaic system installed in the central part of the island.

In 2008, Soneva completely abandoned the use of imported water in plastic bottles, and in 2014 entered into a partnership agreement with the world-wide charity Aquiva Foundation to introduce an innovative desalination system using memsys technology [5]. Today, the resort has not only fully covered its own consumption of fresh water, but also installed similar desalination in Maalhos, the nearest island of the Baa Atoll. It is currently serving Maalhos, but in March 2020 it sho start delivering drinking water to Dharavandhoo and Kihaadhoo ilands.

\section{USE OF SOLAR ENERGY}

The sun is the main natural wealth of the Maldives. According to performed studies, solar radiation in this area ranges from 4.5 to $6.0 \mathrm{~kW} \mathrm{/} \mathrm{m}^{2}$ / day [9]. This energy can be converted into electricity and provide the operation of a desalination plant, lighting and air conditioning of the villas, as well as the movement of electric vehicles, especially taking into account that the cost of photovoltaic systems and batteries has dropped sharply in recent years. However, using only a photovoltaic system based on solar radiation (even if it is enough) is not a completely reliable option for sustainable consumption, so hybrid photo-diesel power plants (PV-Diesel Hybrid Systems) are becoming more and more popular. (Fig.2).

Theoretical calculations of the effectiveness of such systems demonstrate their promise for providing autonomous power supply in areas remote from electric networks [10-12].

In November 2009, the first photovoltaic system in the Maldives with a capacity of $70 \mathrm{~kW}$ was installed in Soneva; it provided 3\% of the energy consumed. After a successful test of the pilot plant, in 2016, a new 624 kW hybrid system was added to it. In 2019, 774.414 kW were produced on the island, which amounted to about $12 \%$ of the total energy. In 2020, it is planned to further increase the performance of solar panels and include powerful batteries in the existing photo-diesel system.

A hybrid photo-diesel power station consists of a photovoltaic system (solar power station), 2.8 MW diesel generators, a battery, and intelligent control system (PV-Diesel EMS) (Fig.2).

Solar panels are located in the central part of the island and are hidden from the eyes of the resort's guests. They have a canopy configuration that allows using the area of land beneath them. The conversion
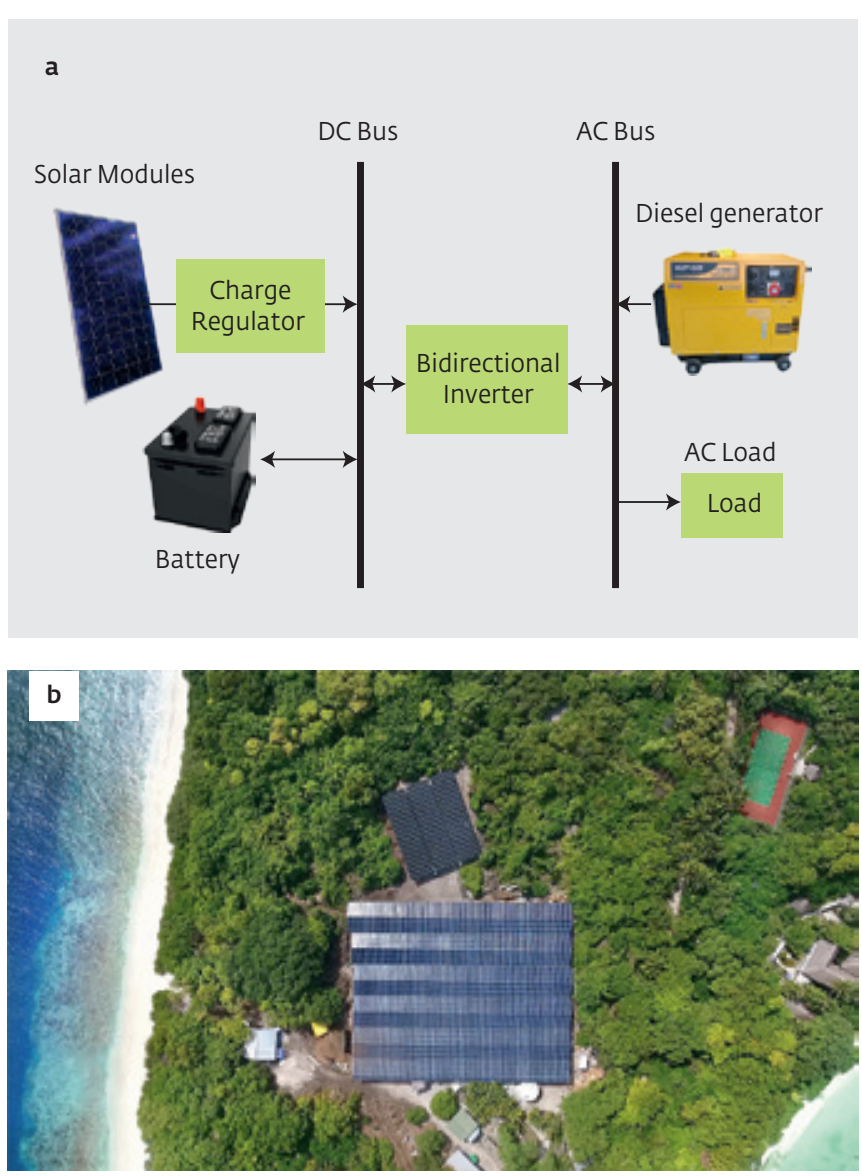

Fig.2. Hybrid photo-diesel power plant scheme (a), solar panels in Soneva Fushi (b)

of direct current (DC) generated by the solar battery into alternating current $(A C)$ is carried out using an invertor. Storage batteries are used to store the excess energy generated by the photovoltaic system in sunny weather. Depending on the situation, the main energy is a photovoltaic system or a diesel generator set. Optimal operation of the installation as a whole is ensured by the PV-Diesel EMS system, which monitors, controls, and optimizes the performance, and coordinates the operation and time of each power source, which reduces fuel consumption and carbon dioxide emissions into the atmosphere.

To reduce energy consumption, simple but effective techniques are additionally used in Soneva Fushi. The resort lives on its own time, which is an hour ahead of the local: this allows to increase daylight hours and reduce electricity consumption. To reduce the cost of air conditioning in a hot tropical climate, the roofs are covered with natural materials; in particular palm leaves and grass, and houses are preferably located in the shade of tall trees. 


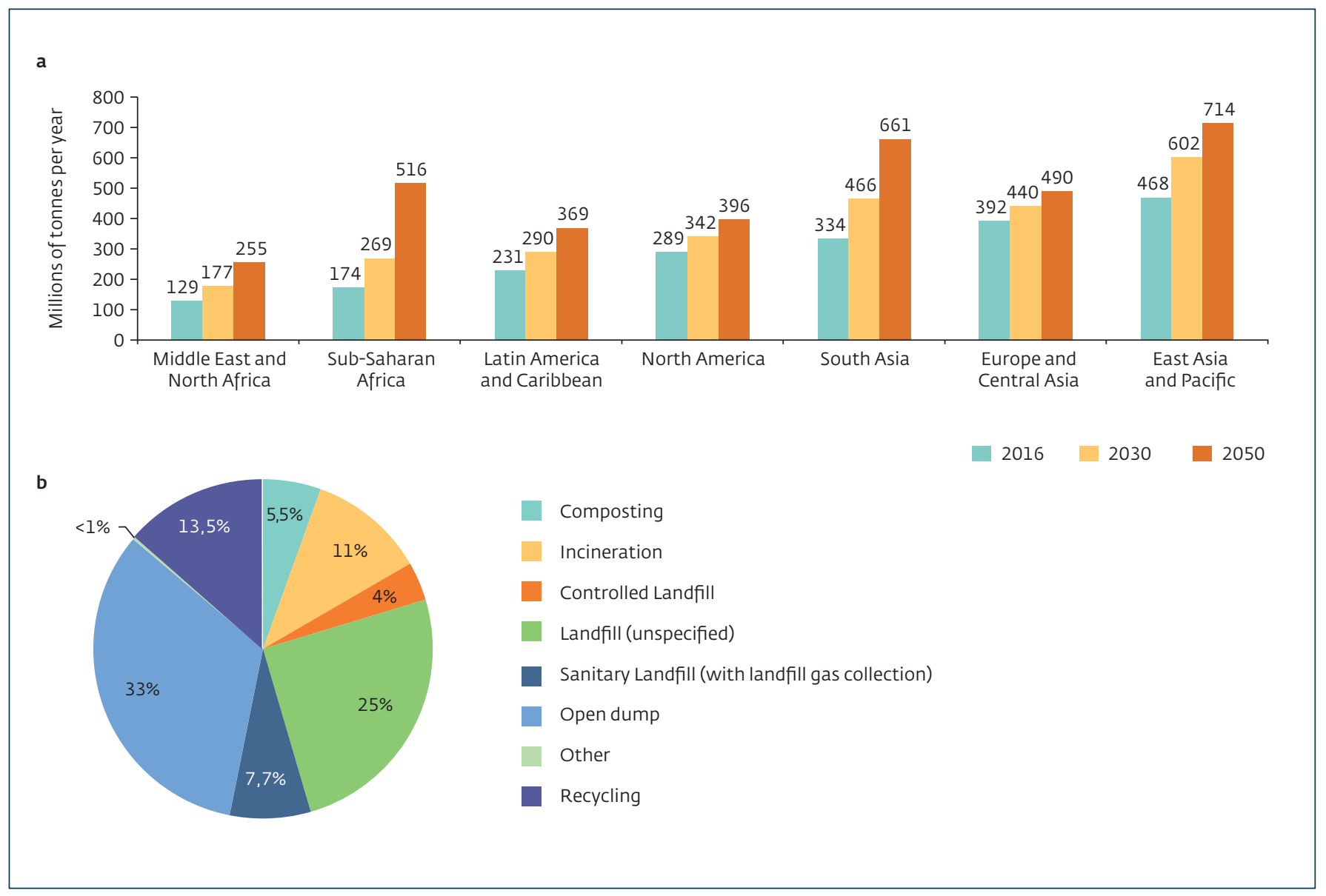

Fig.3. Waste produced annually by region (a), waste management (b)

\section{WASTE-TO-WEALTH}

One of the main environmental problems of the modern world is the problem of waste disposal. According to the World Bank estimates, 2.01 billion tonnes of municipal solid waste is generated annually in the world, with 0.74 $\mathrm{kg}$ per person per day, although this figure varies from 0.11 to $4.54 \mathrm{~kg}$ depending on the region. It is expected that by 2050 the amount of waste will increase to 3.40 billion tonnes [13]. About 37\% of the world waste is dumped and covered with soil, of which only $8 \%$ is disposed in sanitary landfills with landfill gas collection systems, about $33 \%$ of waste goes to open landfills without soil dumping; $11 \%$ is burned in an open fire. Only $19 \%$ of the waste goes to recycling and composting (Fig.3).

A completely different situation is taking place in Soneva Fushi resort: in accordance with the principles of sustainable development, the company recycles $90 \%$ of solid waste in the Eco-Center established on the island in 2008. Moreover, the experts of the Eco-Center, guided by the Waste-to-Wealth program, demonstrate the possibilities of turning waste into valuable resources and even works of art: they create lampshades from cans; melt glass bottles and turn them into vases, candle holders, and glass figurines; and jewelry is made from coconut shells.

The branches of the trees, cut during clearing of the paths and recreational areas, are crushed and mixed with fallen leaves and food waste. This creates an excellent base for compost, providing an optimum ratio of carbon to nitrogen of approximately 30: 1. Raw materials for compost can be conditionally divided into "green" and "brown". Green raw materials such as leaves and grass have a lot of nitrogen, while brown materials like coconut twigs and husk contain carbon. For example, in freshly cut grass, the $\mathrm{C}$ : $\mathrm{N}$ ratio is $15: 1$, and in dry fallen leaves it is 50: 1. To get the best result a competent combination of "green" and "brown" components is necessary. The composting process is based on the decomposition of organic components by aerobic microorganisms: mesophilic and thermophilic bacteria, actinobacteria, fungi and protozoa; hence it is necessary to control the level of humidity and oxygen. Sufficient aera- 
Table 2. Comparative efficiency of coal production plants [15]

\begin{tabular}{|l|c|}
\hline \multicolumn{1}{|c|}{ Plant } & Efficiency \\
\hline Traditional klin & $8-12 \%$ \\
\hline Improved traditional klin & $12-17 \%$ \\
\hline \begin{tabular}{l} 
Industrial technology \\
\hline $\begin{array}{l}\text { ICPS - Improved Charcoal } \\
\text { Production System (Adam Retort } \\
\text { charcoal kiln) }\end{array}$
\end{tabular} \\
\hline
\end{tabular}

tion is ensured provid a combination of rapidly decomposing food waste and hard-to-decompose wood particles, and periodic compost overturning. In addition, active aeration methods are being introduced.

The compost obtained in the Eco-center is mixed with the island's calcareous sandy soil and used to grow greens, vegetables, and mushrooms, which are directly supplied to the resort's restaurants. Transportation costs are minimized and, therefore, carbon dioxide emissions into the atmosphere are reduced due to the resort supplying itself with essential greens and vegetables.

Wood waste and coconut husk are used in a different way: pyrolysis without access to air is used to make charcoal for barbecue and tandoor. An Adam Retort charcoal kiln (Improved Charcoal Production System - ICPS) was installed on the island in 2009[14], and it is able to transform $3 \mathrm{~m}^{3}$ of biomass into $350 \mathrm{~kg}$ of charcoal in 30 hours. Today, the resort fully meets its own charcoal needs.

The efficiency of the retort charcoal kiln is $30-42 \%$, which significantly exceeds the efficiency of other carbonization systems (about 18\%) (Table 2). The process of coal formation consists of two stages. At the first stage, which lasts about 4 hours, ICPS works like a traditional stove, with hot volatile substances from the furnace being sent to the wood-burning chamber and used to dry the wood. As soon as the smoke, consisting primarily of water vapor at the beginning of the process, becomes yellow, the second retort phase begins. Smoke and volatile compounds contained in it are redirected to the furnace using a simple device, and burned, and the generated heat is reused. This technology can reduce air pollution by up to $75 \%$ since the resulting volatile compounds partially burn out during carbonization. Another advantage is that the retort klin has an operating time of about 12 hours

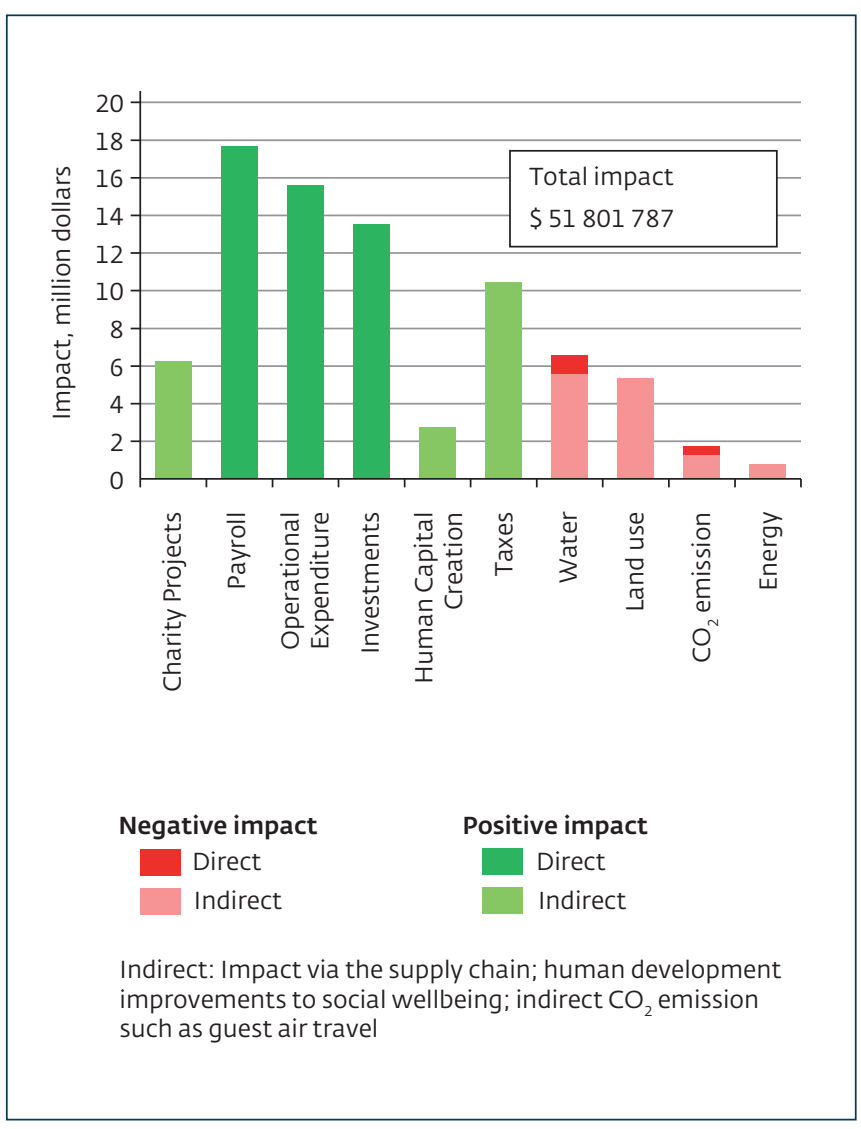

Fig.4. Assessment of the total impact of the company

(plus about 12 hours for cooling) compared to traditional furnaces in which a similar process takes from 4 to 7 days.

The resort's activities are unthinkable without the operation of restaurants, which means that bottle glass and perishable products in expanded polystyrene containers are constantly imported to the island. Soneva produces lightweight building blocks from these packaging materials. Expanded polystyrene is crushed to form small balls, and the glass is ground into powder. Cement is added to the mixture so that the ratio of the ingredients is $70 \%$ polystyrene foam, $20 \%$ glass powder, and $10 \%$ cement. The resulting mass is mixed and molded in the form of bricks. Building blocks cannot be used as load-bearing, but they have high thermal insulation properties, which is important for the tropical climate of the Maldives.

In addition, a glass-blowing workshop that operates on the island, turns about one tonne of bottle glass into works of art every two to three months.

\section{TOTAL IMPACT ASSESSMENT}

In 2016, Soneva developed a new tool to assess the total impact of the company and create a holistic view of the environmental, human, social, economic and financial 
aspects of the business. Along with the profitability of shareholders, it takes into account and evaluates a number of non-financial indicators, which gives a holistic view of understanding risks and opportunities, and maintains a positive impact on society. Every year, the company's activities are evaluated in five categories - natural capital, human capital, social capital, economic capital and taxes (Fig.3) [1].

The impact on natural capital includes $\mathrm{CO}_{2}$ emissions and the use of water and land resources. Importantly, not only direct impacts, but also indirect impacts from the entire supply chain and air transportation of the guests are taken into account. For example, the carbon footprint from guests flying makes up $81 \%$ of the company's total carbon dioxide emissions. Since this component is impossible to minimize, Soneva has been trying to compensate these harmful effects by participating in charitable environmental projects, in particular in a campaign to provide Myanmar's population with low-carbon dioxide stoves, since 2009. Until now, most families in rural Myanmar have cooked on an

\section{LITERATURE}

1. Soneva Total Impact Assessment 2018, https://s3-euwest-1.amazonaws.com/websites-wordpress-uploads/ www.soneva.com/wp-content/uploads/2019/04/Soneva-Total-Impact-Assessment-2018.pdf

2. Pascale Compain Solar Energy for Water desalination // Procedia Engineering 46 ( 2012 ) 220-227

3. Zaragoza G. 1, Andrés-Mañas J.A 1 and Ruiz-Aguirre A., Commercial scale membrane distillation for solar desalination // npj Clean Water (2018) 1:20 ; doi:10.1038/s41545-018-0020-z

4. Swaminathan J., McGovern R.K., Hyung-Won Chung, Warsinger D.E.-M., Lienhard J.H. MULT-EFFECT MEMBRANE DISTILLATION // US 2017/0014773 A1, 2017

5. Sustainable seawater desalination solution introduced in Maldives Islands. https://www.waterworld.com/ drinking-water/potable-water-quality/article/16215623/ sustainable-seawater-desalination-solution-introduced-in-maldives-islands

6. Kiefera F., Spinnlera M., Sattelmayer T. Multi-Effect Vacuum Membrane Distillation Systems: Model Derivation and Calibration // Desalination 438:97-111 · July 2018 DOI: 10.1016/j.desal.2018.03.024

7. Technology of thermal membrane distillation // https:// www.memsys.eu/technology/membrane-distillationtechnology.html

8. Zhao K., Heinzl W., Wenzel M., Büttner S., Bollen F., Lange G., Heinzl S., Sarda N. Experimental study of the memsys vacuum-multi-effect-membrane-distillation (V-MEMD) module // Desalination 323 (2013) 150-160 open fire. Switching to the state-of-the-art, cost-effective Envirofit M5000 stoves reduces deforestation and greenhouse gas emissions. As a result, the total activity of the company since 2012 has become carbon neutral.

About $82 \%$ of the burden on natural capital falls on the production of food and beverages, so measures were taken to increase productivity, which in $2018 \mathrm{grew}$ to exceed $\$ 160,000$.

Investments in human capital include the Women in Soneva program, which aims to attract Maldivian women into the hospitality industry.

Social capital includes, in particular, the Soneva Ocean Stewards swimming training program for Maldivian children and the Soneva Water program that provides drinking water in reusable glass bottles to the residents of the neighboring islands.

$$
* * * * *
$$

Thus, the activities of the Soneva Resort demonstrate that successful business, social and environmental progress can go hand in hand.

9. Renné D., George R., Marion B., Heimiller D. Solar Resource Assessment for Sri Lanka and Maldives. National Renewable Energy Laboratory // Solar Energy. 1991. V. 47. No. 5. DOI: 10.2172/15004299

10. Sudradjat A., Kantosa E. Photovoltaic-Diesel Hybrid System How to Adapt to Real Site Conditions // KnE Energy. 2015. P. 1-4. DOI http://dx.doi.org/10.18502/ken. v1i1.328,

11. Yamegueu D., Azoumah Y., Py X., Kottin H. Experimental analysis of a solar PV/diesel hybrid system without storage: Focus on its dynamic behavior // Electrical Power and Energy Systems 44 (2013) 267-274. http://dx.doi. org/10.1016/j.ijepes.2012.07.027,

12. Ismail M.S., Moghavvemi M., Mahlia T.M.I. DESIGN OF A PVIDIESEL STAND ALONE HYBRID SYSTEM FOR A REMOTE COMMUNITY IN PALESTINE // Journal of Asian Scientific Research. 2012. 2(11):599-606

13. What a Waste 2.0. A Global Snapshot of Solid Waste Management to 2050. 2018. International Bank for Reconstruction and Development. The World Bank https:// datatopics.worldbank.org/what-a-waste/trends_in_ solid_waste_management.html

14. Adam J.C. Improved and more environmentally friendly charcoal production system using a low-cost retort-kiln (Eco-charcoal) // Renewable Energy. 34 (2009) 1923-1925

15. Charcoal Production. GIZ HERA Cooking Energy Compendium // https://energypedia.info/wiki/Charcoal_Production 


\section{pharmtech}

Международная выставка оборудования, сырья и технологий для фармацевтического производства

\section{Забронируйте стенд}

$10-13$

НОЯБРЯ

2020

Россия, Москва

МВЦ «Крокус Экспо»

pharmtech-expo.ru 